\title{
Características das Frentes Frias Causadoras de Chuvas Intensas no Leste de Santa Catarina
}

\author{
Marcelo Seluchi, Cássia Beu, Kelen M. Andrade \\ Centro Nacional de Monitoramento e Alertas de Desastres Naturais, \\ São José dos Campos, SP, Brasil.
}

Recebido em 20 de Agosto de 2015 - Aceito em 25 de Maio de 2016

\begin{abstract}
Resumo
O presente trabalho analisa as características principais das frentes frias causadoras de chuvas intensas no litoral do Estado de Santa Catarina, com a finalidade de melhorar o conhecimento e a previsão desse tipo de situação. Para isso, foi feita uma climatologia sinótica das frentes frias, utilizando reanálises CFSR do NCEP e dados de precipitação do CPTEC/INPE no período 1998-2010, a partir dos quais foram separados 5\% das frentes frias mais chuvosas da série. Os resultados mostram que as frentes frias que provocam chuvas mais volumosas ocorrem ao longo de todo o ano, associadas à penetração de cavados frios, intensos e pouco baroclínicos nos níveis médios e altos da atmosfera. A lenta evolução da situação meteorológica permite a intensificação de um cavado na baixa troposfera, que provoca a gradativa intensificação da instabilidade termodinâmica sobre o leste de Santa Catarina, através da advecção de calor e umidade desde a Amazônia. A frente fria que dispara a precipitação apresenta forte inclinação nos baixos níveis e lento deslocamento. Em geral, a situação meteorológica apresenta poucas variações sazonais e pode ser identificada, em média, com pelo menos $48 \mathrm{~h}$ de antecedência.
\end{abstract}

Palavras-chave: Santa Catarina, frentes frias, extremos de precipitação

\section{Characteristics of Cold Fronts Causing Heavy Rainfall Over Eastern Santa Catarina}

\begin{abstract}
This article analyze the main characteristics of cold fronts yielding heavy rains on the coast of the State of Santa Catarina with the further purpose of improving its knowledge and prediction. A synoptic climatology was performed using NCEP CFSR reanalyzes and CPTEC/INPE precipitation data for the1998-2010 period, considering 5\% of the wettest cases. Results showed that cold fronts causing heaviest precipitation have a rather uniform temporal distribution along the year, associated with strong, cold and rather barotropic troughs at middle and upper levels. The slow meteorological evolution allows a progressive low-level trough deepening that increase temperature and moist advection from the Amazon to eastern Santa Catarina thus intensifying thermodynamic instability. The cold front that triggers precipitation has strong low-level tilt and slow movement. Atmospheric conditions linked to frontal passages causing heavier precipitation have minor seasonal variability and can be detected at least 48 hours in advance.
\end{abstract}

Keywords: Santa Catarina, cold fronts, precipitation extremes.

\section{Introdução}

Pesquisas recentes mostram um aumento considerável no número de desastres naturais (DN) no mundo (sumarizadas em Marcelino, 2008), assim como da sua gravidade tanto do ponto de vista humano quanto financeiro. Diversos fatores contribuem para esse fenômeno, como o aumento explosivo da população, a desigualdade social (que motiva a ocupação desordenada do território), alterações do uso do solo (mudanças de culturas, desmatamento, impermeabilização do solo para construção de cidades, etc), além das alterações climáticas, tanto de caráter natural como antropogênicas.

Segundo a metodologia de Cavallo e Noy (2009) e baseado nas informações dos anos 2008 a 2011, o Brasil

Autor de correspondência: Marcelo Seluchi, marcelo.seluchi@cemaden.gov.br. 
apresenta uma taxa de mortalidade de aproximadamente 2,5 pessoas/milhão de habitantes, muito superior à média mundial ( $\sim, 5$ pessoa/milhão de habitantes) $\mathrm{e}$, inclusive, à média da América Latina ( $\sim 1,0$ pessoa/milhão de habitantes). Esse fato resulta de diversos fatores como a ocorrência de chuvas intensas, típicas do clima tropical úmido, a presença de topografia irregular e o crescimento desordenado da população. A junção desses fatores, em maior ou menor medida, determina as regiões do país com maiores índices de vulnerabilidade aos DNs.

A porção leste do estado de Santa Catarina, e em particular a Região do Vale do Itajaí, apresenta um longo histórico de DNs. Segundo o Atlas Brasileiro de Desastres Naturais, o Estado de Santa Catarina é o terceiro (depois de Rio Grande do Sul e Minas Gerais) com o maior número de DNs, mesmo com uma extensão territorial consideravelmente menor em comparação com esses dois estados. Sua localização entre as latitudes médias e subtropicais permite que tanto as massas de ar tropical quanto os sistemas frontais influenciem frequentemente essa região (Ribeiro et al., 2015, Cavalcanti e Kousky 2009). A presença habitual dos jatos de altos (Escobar, 2009) e baixos níveis (Salio et al., 2007) e a proximidade relativa do Oceano Attântico, completam um quadro meteorológico propício para a ocorrência de tempestades severas. Segundo Brooks e Craven (2003) e Brooks (2006) a região localizada a leste dos Andes entre os $25^{\circ} \mathrm{S}$ e $35^{\circ} \mathrm{S}$, onde se encontra o Estado de Santa Catarina, é a que apresenta as condições mais favoráveis para a ocorrência de tempestades severas no mundo, inclusive superiores às observadas nas planícies dos Estados Unidos da América. Em particular, a região do Vale do rio Itajaí já foi alvo de desastres naturais que causaram grandes impactos humanos e econômicos, entre os quais se destacam as severas inundações de 1974, 1983, 1987, 1992, 1997 e 1998, além da tragédia ocorrida em novembro de 2008 onde 137 pessoas perderam a vida.

Sendo as frentes frias um dos principais sistemas causadores de chuva na Região Sul do Brasil (Catto et al., 2012), as considerações anteriores enfatizam a necessidade de aprofundar-se o conhecimento sobre as condições nas quais os sistemas frontais provocam chuvas intensas sobre o Estado de Santa Catarina e, em particular, sobre o extremo nordeste do estado, onde se encontra o Vale do Itajaí. Em consequência, o principal objetivo deste trabalho é estabelecer as condições meteorológicas mais relevantes associadas à passagem de frentes frias causadoras de chuvas intensas no litoral do Estado de Santa Catarina, com a ulterior finalidade de compreender os mecanismos dinâmicos e termodinâmicos atuantes e de melhorar a previsão desse tipo de situação.

\section{Dados e Metodologia}

Para atingir os objetivos deste trabalho, foi realizada uma climatologia das frentes frias na porção leste de Santa Catarina, na região delimitada pela caixa 2 da Fig. $1\left(29^{\circ} \mathrm{S}\right.$

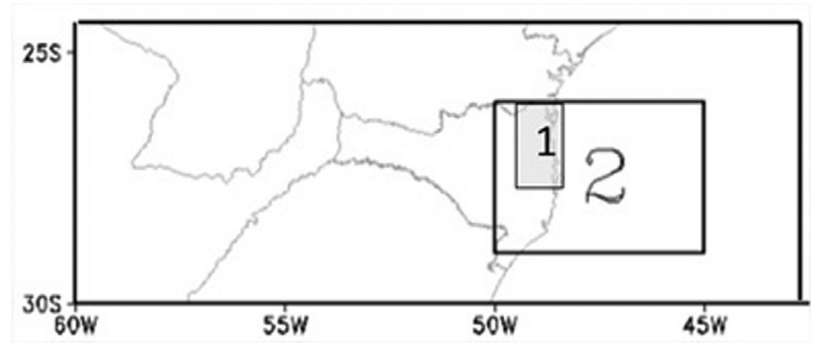

Figura 1 - Áreas selecionadas para estudo.

a $26^{\circ} \mathrm{S}$ e $50^{\circ} \mathrm{O}$ a $45^{\circ} \mathrm{O}$ ). Foram utilizadas, para isso, reanálises do Climate Forecast System Reanalysis (CFSR), desenvolvidas pelo National Center Environmental Prediction (NCEP) (Saha et al., 2010). Esses dados possuem resolução horizontal espectral T382L64, com arquivos disponíveis para os usuários na resolução de $0.5^{\circ}$. O período utilizado para a climatologia foi de 1998 a 2010, em função da disponibilidade de dados de chuva adequados. Os dados de precipitação provêm do MERGE/INPE, uma combinação entre observações pluviométricas e informações do TRMM, com resolução de $0.25^{\circ}$, descritos em Rozante et al. (2010).

Para a identificação dos sistemas frontais foi utilizado um critério semelhante ao definido por Andrade (2005): 1-aumento da pressão ao nível médio do mar maior que $2 \mathrm{hPa}$; 2 -queda da temperatura maior que $2{ }^{\circ} \mathrm{C}$ no nível de $925 \mathrm{hPa}$ e 3-mudança na direção do vento de quadrante norte para quadrante sul no nível de $925 \mathrm{hPa}$. Essas três mudanças devem ocorrer simultaneamente e em dias consecutivos (prazo de $24 \mathrm{~h}$ ), considerando apenas dados das $12 \mathrm{Z}$. Os limiares de $2 \mathrm{hPa}$ e $2{ }^{\circ} \mathrm{C}$ foram tomados de Cavalcanti e Kousky (2003). Desta maneira, foram identificados 1221 sistemas frontais ao longo dos 13 anos analisados. A seleção das frentes frias associadas a extremos de chuva para o Vale do Itajaí, dentro da área 1 da Fig. 1, foi realizada utilizando-se uma metodologia semelhante à proposta por May (2004) e Teixeira e Satyamurty (2007), baseada no cálculo dos quantis de precipitação diária. Assim, uma vez estabelecida a chuva associada a cada frente fria sobre a área 1 da Fig. 1 (Vale do Itajaí), foram separadas duas sub-amostras correspondentes aos casos cuja precipitação está dentro dos percentis 5\% (casos "secos") e $95 \%$ (casos "chuvosos"), respectivamente. Arredondando os limiares, foram consideradas como frentes frias chuvosas aquelas que provocaram precipitações superiores a $20 \mathrm{~mm} / 24 \mathrm{~h}$ (81 casos) e como frentes frias secas aquelas cujo acumulado pluviométrico foi inferior a $2 \mathrm{~mm} / 24 \mathrm{~h}$ ( 76 casos).

A seguir, foi realizada uma "composição de casos" das frentes frias escolhidas, desde 2 dias antes (dia-2) até o dia da sua passagem pelo Vale do Itajaí (dia 0), seguindo uma metodologia semelhante à empregada, por exemplo, por Garreaud (2000). Posteriormente, foram obtidas as médias dos campos compostos e suas anomalias, para diversas variáveis troposféricas e para cada tipo de frente fria. As 
anomalias foram calculadas com respeito à média do período 1998-2010, ponderando-se as respectivas médias (anual ou semestral) pelo número de casos de frentes frias (chuvosas ou secas) selecionados em cada mês. Finalmente, para fins de comparação, foi calculada a diferença entre os campos correspondentes aos casos chuvosos e não chuvosos. Para esse cálculo as diferenças também foram ponderadas levando-se em conta o número de casos de cada tipo observados em cada mês do período considerado.

\section{Resultados e Discussão}

A Tabela 1 mostra o número de frentes frias chuvosas e não chuvosas selecionadas nos semestres quente (novembro-março) e frio (abril-setembro), onde se destaca uma distribuição relativamente uniforme em ambos os casos. Ao longo dos 13 anos analisados, a frequência anual de frentes frias chuvosas e não chuvosas mostrou-se bastante variável, conforme é mostrado na Fig. 2. No ano de 1998, por exemplo, houve predomínio de eventos chuvosos (10 casos) enquanto que no ano de 2004 predominaram os eventos não chuvosos, com 11 casos. Nos 4 últimos anos do período estudado, os casos chuvosos predominaram novamente. Devido à longitude da série analisada, não foi possível identificar nenhuma associação com ondulações de grande escala e/ou de longo período.

\subsection{Precipitação}

A Fig. 3a mostra os campos médios de precipitação diária correspondentes aos 81 casos de frentes frias causa- doras chuvas intensas sobre o Vale do Itajaí ao longo do ano. Mesmo se tratando de uma média anual, o padrão dominante mostra uma clara conexão entre a precipitação frontal e a convecção amazônica (típica do verão), que sofre uma interrupção (ou diminuição) na parte central do Brasil. Ao analisar os campos de chuva dos dias que antecedem a passagem dos sistemas frontais pela área de estudo, verifica-se que com dois dias de antecedência (Fig. 3c) as precipitações mais abundantes se localizam sobre a Bacia do Prata, com maior intensidade sobre o Rio Grande do Sul e o oeste de Santa Catarina, mas sem mostrar uma distribuição espacial alongada, típica de sistemas frontais. Nesse estágio o alinhamento com a convecção tropical é menos evidente, provavelmente devido à grande diferença latitudinal entre as áreas precipitantes.

Nas 24 h seguintes, ou seja, um dia antes da passagem dos sistemas frontais pelo Vale do Itajaí (Fig. 3b), as maiores precipitações ficam concentradas entre o centro-norte do Rio Grande do Sul e o sul do Paraná. Chama a atenção que nesse dia os acumulados sobre a área de interesse são superiores aos registrados no dia da passagem das frentes frias, sugerindo a possibilidade de convecção pré-frontal. A análise dos campos de precipitação média sugere que os sistemas frontais com potencial para causar chuva intensa no Vale do Itajaí deslocam-se lentamente nas $48 \mathrm{~h}$ anteriores e produzem também acumulados significativos ao sul da área de estudo.

Ao analisar-se as diferenças sazonais (figuras não mostradas), pode notar-se que no semestre frio as chuvas se

Tabela 1 - Número de casos estudados.

\begin{tabular}{lccc}
\hline & Semestre quente (outubro a março) & Semestre frio (abril a setembro) & Total \\
\hline Frentes frias chuvosas & 45 & 36 & 81 \\
Frentes frias não chuvosas & 38 & 38 & 76 \\
Total & 83 & 74 & 157 \\
\hline
\end{tabular}

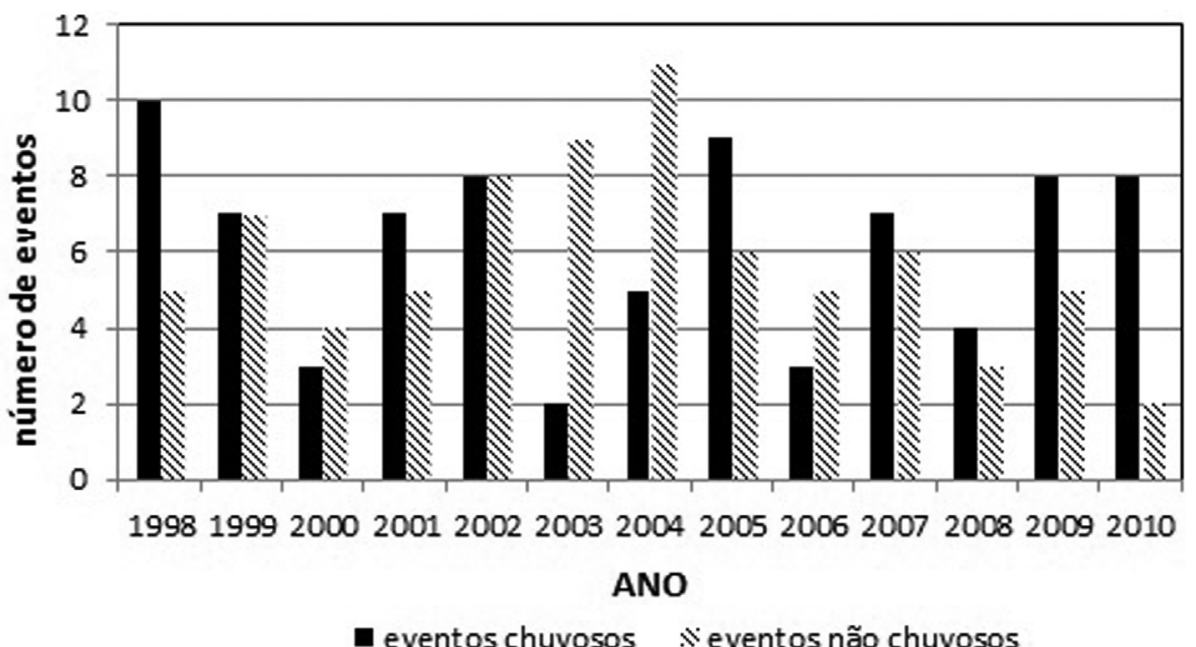

Figura 2 - Distribuição anual de sistemas frontais sobre o leste de Santa Catarina. 
(a)

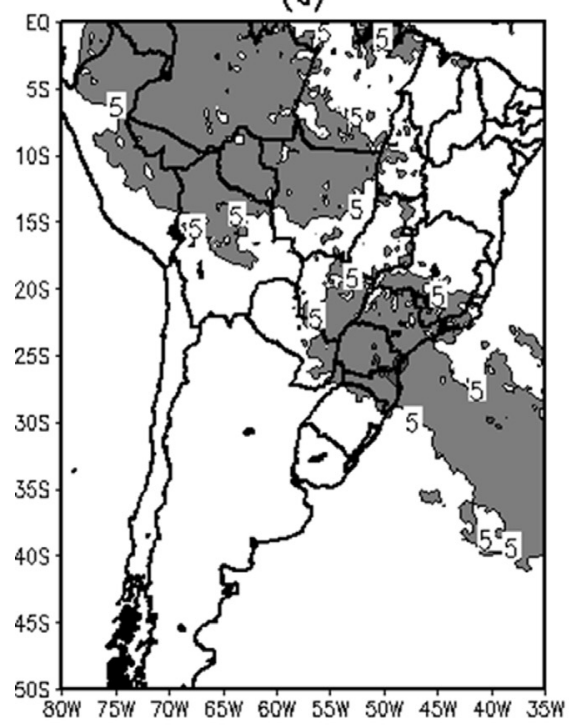

(b)

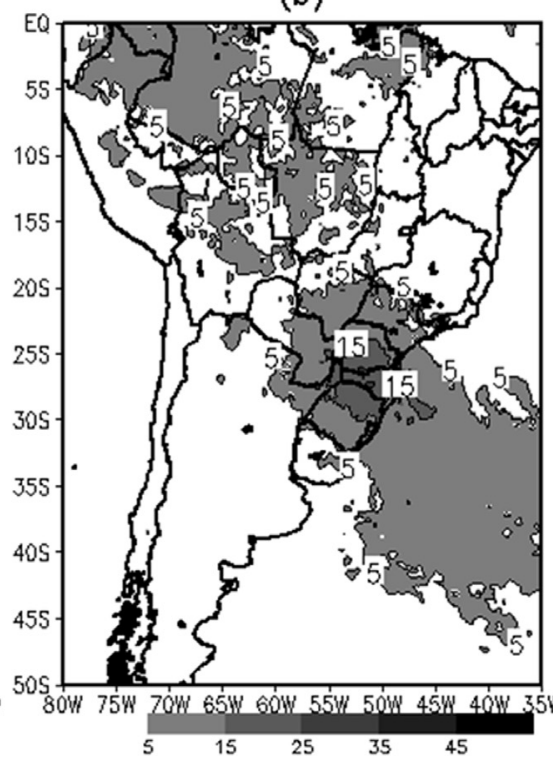

(c)

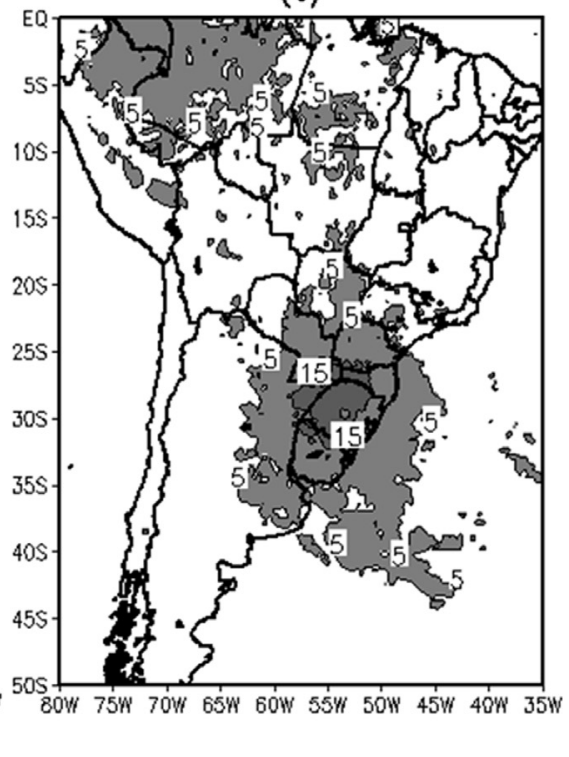

Figura 3 - Campo médio de precipitação ( $\mathrm{mm} /$ dia) correspondente a: a) o dia da passagem dos sistemas frontais; b) um dia antes e c) dois dias antes da passagem dos sistemas frontais que provocam chuvas mais intensas no Vale do Itajaí.

estendem menos sobre o interior do continente e mais sobre o Oceano Atlântico adjacente. No semestre quente, a banda precipitante se alinha claramente desde a Amazônia até o Oceano Atlântico, estando o Vale do Itajaí localizado próximo da borda sul desta banda, dentro de uma região de maior precipitação relativa.

Nos casos não chuvosos (figuras não mostradas), durante a passagem das frentes frias pelo Vale do Itajaí, a precipitação, além de ser comparativamente mais fraca, ocorre sobre o Oceano Atlântico, separada do continente. Nos dois dias que antecedem essa situação, a chuva localiza-se mais para o sul do que nos casos chuvosos, provavelmente evidenciando um deslocamento mais rápido dos sistemas frontais.

\subsection{Campos médios e de anomalias dos eventos chuvosos}

Esta seção visa analisar as principais características dinâmicas e termodinâmicas da atmosfera, associadas à atuação de frentes frias com potencial para causar chuvas extremas sobre o Vale do Itajaí. Sendo que os casos escolhidos apresentam uma frequência relativamente uniforme nos semestres quente e frio, a análise realiza-se para todos os casos selecionados ao longo do ano. As diferenças sazonais mais relevantes serão discutidas brevemente na seção 3.4 .

A Fig. 4 apresenta os campos médios obtidos a partir dos compostos correspondentes ao dia da passagem das frentes frias chuvosas sobre o Vale do Itajaí, que ilustram as características principais observadas nesse dia na troposfera baixa, média e alta. No campo de pressão (Fig. 4a contornos), identifica-se claramente um cavado frontal nas proximidades da costa de Santa Catarina, estendendo-se desde o Oceano Atlântico Sul em direção ao Estado de São Paulo. As características frontais do cavado podem ser comprovadas a partir da advecção diferencial de temperatura (espessura 500/1000 $\mathrm{hPa}$ ) na sua vanguarda e retaguarda, assim como pela presença de um anticiclone frio com características pós-frontais sobre o centro e oeste da Argentina, centrado aproximadamente sobre $40^{\circ} \mathrm{S}$ e $70^{\circ} \mathrm{O}$. O campo de espessura 500/1000 hPa (linhas tracejadas na Fig. 4a) mostra um gradiente considerável entre o leste de Santa Catarina e $40^{\circ} \mathrm{S}$, compatível com a presença de um sistema frontal. A frente fria pode ser também claramente detectada no campo de $850 \mathrm{hPa}$ (Fig. 4b), através do forte gradiente de umidade específica (contornos) e do campo de vento. Destaca-se que, enquanto o sistema frontal está localizado ligeiramente a leste do Vale do Itajaí no nível de superfície, o vento de noroeste sobre essa região indica uma situação ainda pré-frontal em $850 \mathrm{hPa}$ e, portanto, a presença de uma rampa frontal bem inclinada. O escoamento de noroeste apresenta um máximo relativo imediatamente ao noroeste do Vale do Itajaí, dentro de uma massa de ar com características homogêneas de umidade. Em contraste, uma forte advecção de ar mais frio e seco pode ser detectada nas proximidades do extremo sul do Brasil. Subjetivamente, a intensidade dos gradientes de pressão, espessura $500 / 1000 \mathrm{hPa}$, umidade específica em $850 \mathrm{hPa}$, assim como o cisalhamento horizontal de vento nesse nível, permitem deduzir a presença de uma frente de intensidade considerável. Esse resultado é interessante, levando-se em conta que os casos escolhidos no semestre quente (45) superam ligeiramente os selecionados no semestre frio (36).

Nos níveis médios (500 hPa, Fig. 4c), o cavado frontal aparece bem definido sobre o Oceano Atlântico ao sul de $40^{\circ} \mathrm{S}$. Sobre o continente, ao norte de $35^{\circ} \mathrm{S}$, observa-se um 

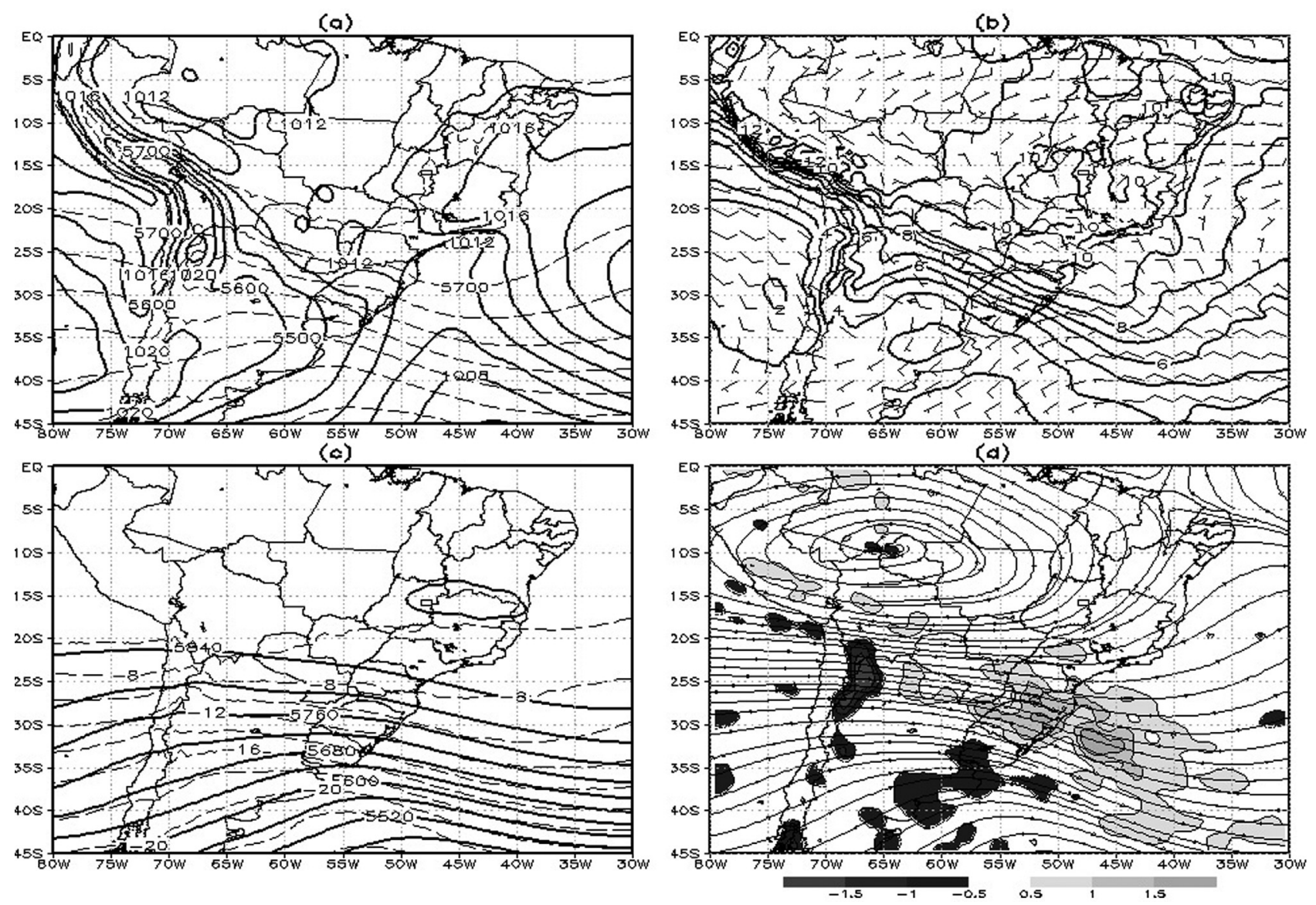

Figura 4 - Campos médios de a) pressão reduzida ao nível médio do mar (contornos, hPa) e espessura 500/1000, linhas tracejadas, hPa (m), b) vento (barbelas, $\mathrm{m} / \mathrm{s}$ ) e umidade específica (contornos, $\mathrm{g} / \mathrm{kg}$ ) em $850 \mathrm{hPa}$, c) altura geopotencial (contornos, mgp) e temperatura (linhas tracejadas, ${ }^{\circ} \mathrm{C}$ ) em 500 $\mathrm{hPa}$, d) linhas de corrente e divergência (tons de cinza, $10^{-5} \mathrm{~s}^{-1}$ ) em $250 \mathrm{hPa}$ correspondente ao dia de passagem de frentes frias que causam chuvas mais intensas no Vale do Itajaí.

cavado duplo, sendo que a onda associada à frente fria apresenta longitude menor, estrutura fria e baixa baroclinia (isoípsas e isotermas praticamente paralelas). O campo de temperatura (linhas tracejadas) evidencia um intenso gradiente térmico ao sul de $25^{\circ} \mathrm{S}$, de aproximadamente $12{ }^{\circ} \mathrm{C}$ $\mathrm{em} 15^{\circ}$ de latitude, condizente com a presença da frente fria nos níveis médios.

Nos altos níveis (Fig. 4d), o cavado aparece bem definido pelas linhas de corrente, associado à forte divergência (cinza claro) sobre o sul do Brasil e o oceano adjacente. A escassa inclinação desse sistema entre 500 e $250 \mathrm{hPa}$ é outro indicador da relativamente baixa baroclinia.

A Fig. 5 mostra os campos de anomalias médias (com respeito à média do período 1998-2010) dos casos de frentes frias chuvosas no Vale do Itajaí. As anomalias de pressão (sombreadas) denotam a passagem de uma onda baroclínica (observar a defasagem entre a onda de massa e a onda térmica), onde as maiores anomalias negativas se estendem sobre o Oceano Atlântico, mas apresentam um máximo relativo entre o leste de Santa Catarina e o extremo sul de São Paulo. O campo de espessura 500/1000 hPa (contornos) mostra que a máxima baroclinia e o maior declínio de temperatura, encontram-se imediatamente ao sul do Vale do Itajaí. O forte gradiente nas anomalias de pressão e espessura observado sobre o sul do Brasil (ao sul do Vale do Itajaí) demonstra uma importante advecção fria anômala. Mais para o oeste, a anomalia anticiclônica (cinza escuro) exibe o típico padrão associado a passagens de anticiclones pós-frontais pela Cordilheira dos Andes (Gan e Rao, 1994; Seluchi et al., 2006)

A anomalia do campo de vento em $850 \mathrm{hPa}$ (representada pelas barbelas na Fig. 5b) mostra um vento anômalo de noroeste, desde o oeste da Amazônia até Santa Catarina, que circunda uma extensa anomalia ciclônica a leste da América do Sul. Esse canal de ventos de noroeste permite um transporte anômalo de umidade ao norte e sobre a região frontal. Como resultado, as anomalias positivas de umidade sobre o Vale do Itajaí (sombreado claro) contribuem para aumentar a instabilidade termodinâmica na região. A partir das anomalias de vento é possível inferir que a frente fria no nível de $850 \mathrm{hPa}$ encontra-se, em média, ao sul e oeste de Santa Catarina, confirmando a inclinação acentuada da rampa frontal entre a superfície e esse nível. A baroclinia acentuada na baixa troposfera contrasta com a 
(a)
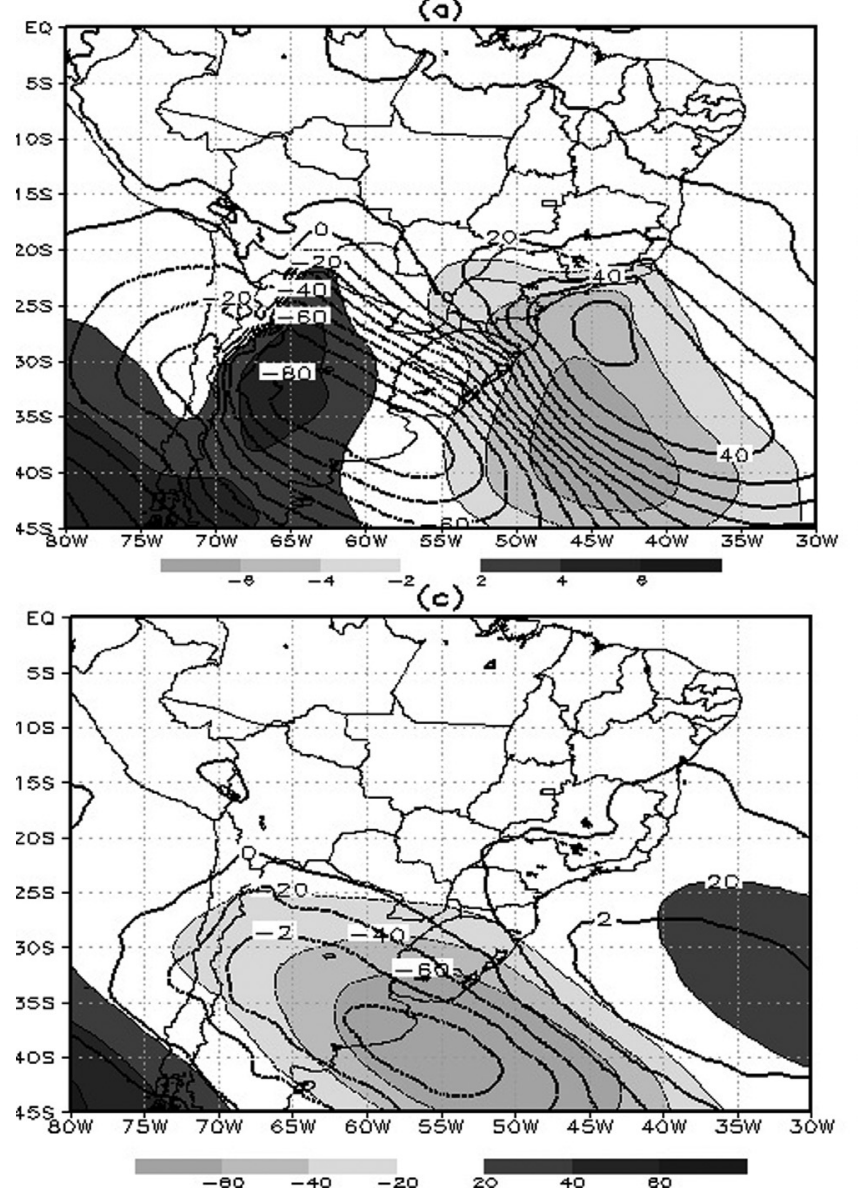

(b)
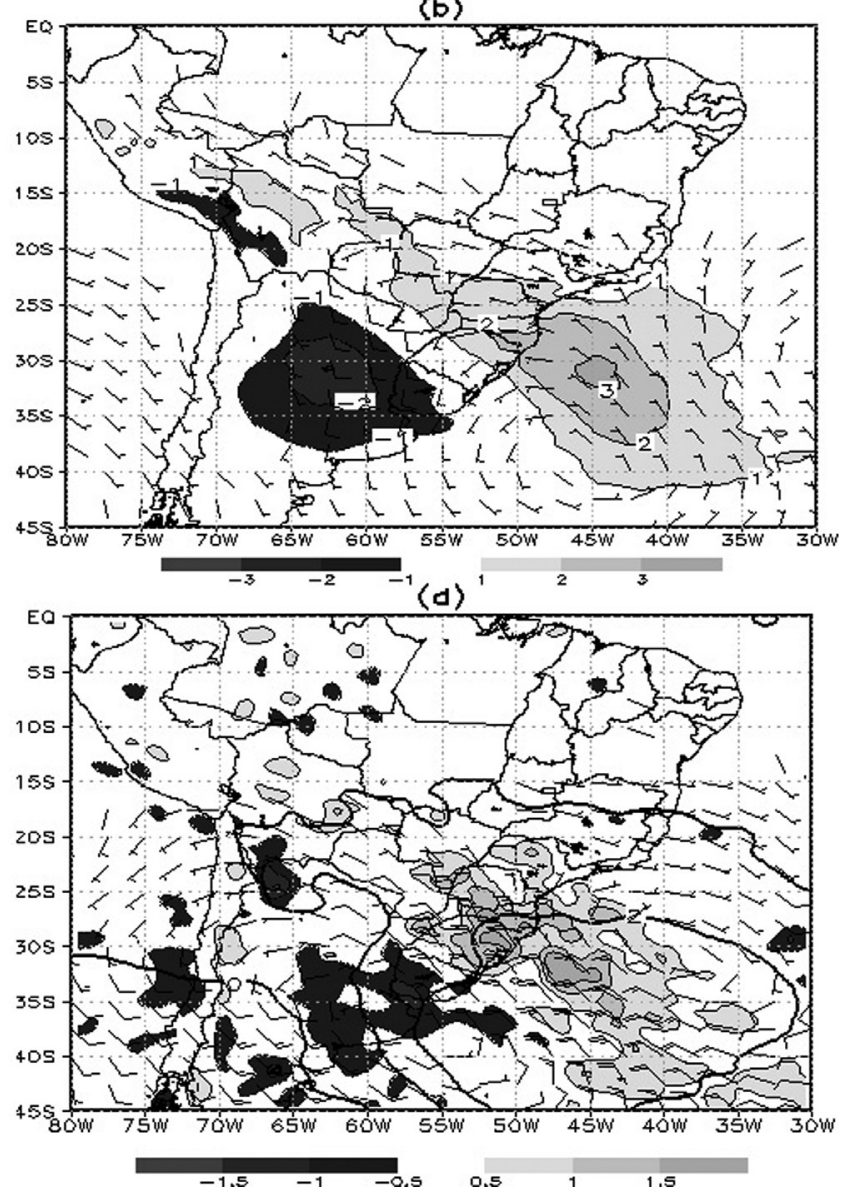

Figura 5 - Anomalias médias de: a) pressão reduzida ao nível do mar (tons de cinza, hPa) e espessura 500/1000 hPa (contornos, m), b) vento (barbelas, $\mathrm{m} / \mathrm{s}$ ) e umidade específica (tons de cinza, $\mathrm{g} / \mathrm{kg}$ ) em $850 \mathrm{hPa} \mathrm{c}$ ) altura geopotencial (tons de cinza, mgp) e temperatura (contornos, ${ }^{\circ} \mathrm{C}$ ) em $500 \mathrm{hPa}, \mathrm{d}$ ) vento (barbelas, $\mathrm{m} / \mathrm{s}$ ), de temperatura (contornos, ${ }^{\circ} \mathrm{C}$ ) e de divergência (tons de cinza, $\mathrm{s}^{-1}$ ) em $250 \mathrm{hPa}$, no dia da atuação dos sistemas frontais que causam chuvas mais intensas no Vale do Itajaí.

menor inclinação do cavado entre os níveis médios e altos. Ao sul da região frontal observa-se o transporte anômalo de ar seco desde o sul, porém comparativamente menos intenso que o transporte pré-frontal de umidade desde o noroeste.

No nível de $500 \mathrm{hPa}$ (Fig. 5c) destaca-se a anomalia negativa de geopotencial (em cinza claro) associada ao sistema frontal, vinculado a um trem de onda com leve orientação de sudoeste para nordeste. Diferentemente do que ocorre na baixa troposfera, a defasagem entre a onda de massa (área sombreada) e térmica (representada pelas anomalias de temperatura, em linhas contínuas) é muito menor neste nível, confirmando a menor baroclinia nos níveis mais elevados. Além disso, as anomalias pós-frontais neste nível são comparativamente mais intensas que as pré-frontais, também ao contrário do que ocorre nos baixos níveis. No nível de $250 \mathrm{hPa}$ (Fig. 5d), as anomalias de vento de noroeste denotam a intensificação do jato de altos níveis. As anomalias positivas de temperatura (contornos) estão, muito provavelmente, vinculadas a um abaixamento anômalo da tropopausa no setor pós-frontal evidenciando uma menor espessura da troposfera e presença de perturbações intensas (Hirschberg e Fritsch,1991).

Em resumo, as frentes frias que causam chuvas abundantes sobre o Vale do Itajaí estão precedidas por condições termodinâmicas favoráveis (ambiente quente e úmido) associadas a perturbações intensas nos níveis médios (cavados frios), assim como forte divergência e abaixamento da tropopausa nos altos níveis.

\subsection{Campos precursores}

Com o objetivo de identificar características que possam auxiliar na previsão das situações causadoras de chuvas intensas no Vale do Itajaí, os campos de anomalias foram também calculados para as 24 e $48 \mathrm{~h}$ anteriores (denominados "dia-1" e "dia-2") à passagem da frente fria.

A Fig. 6 mostra que dois dias antes da passagem de frentes frias chuvosas pelo estado de Santa Catarina, existem indícios da sua proximidade em todos os níveis troposféricos. Em geral, prevalecem condições claramente préfrontais sobre latitudes subtropicais, como a presença da Baixa do Chaco (Seluchi e Saulo, 2012) associada a um 
(a)

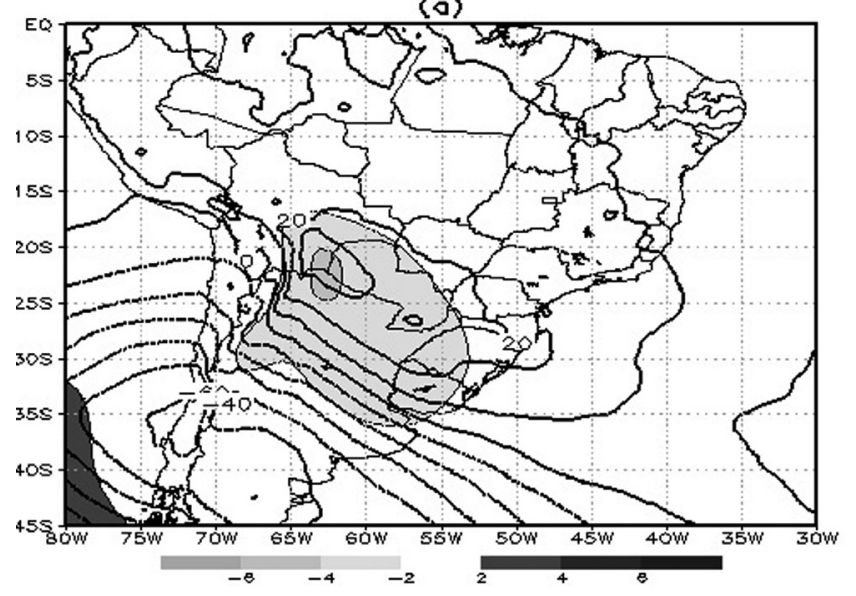

(c)

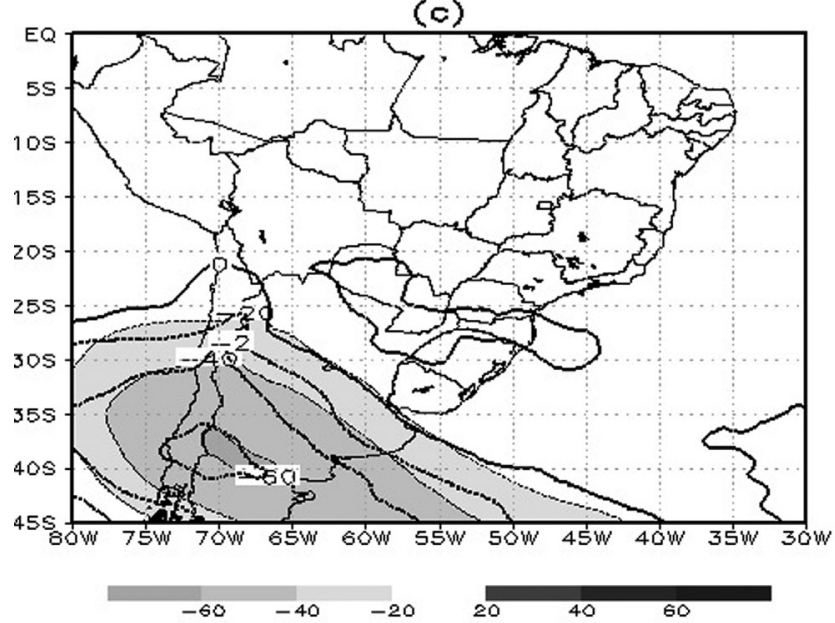

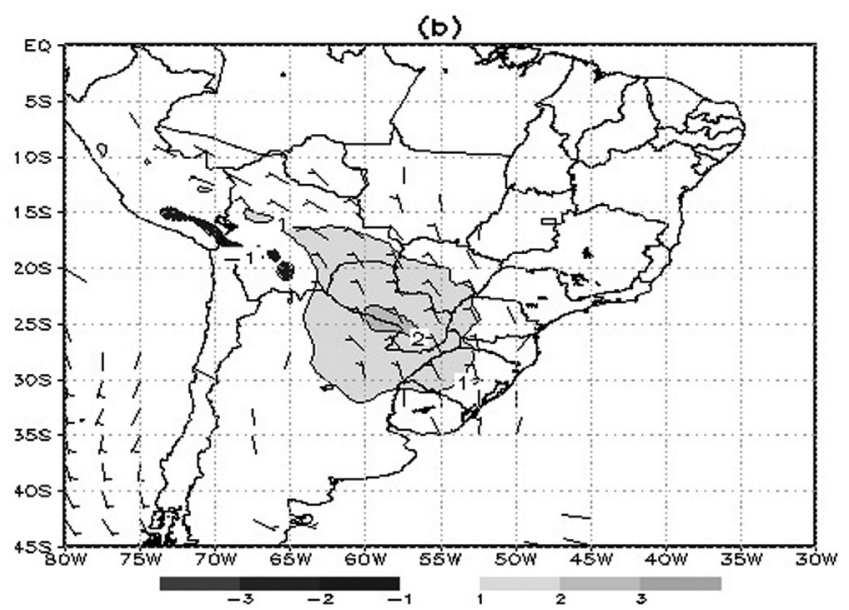

(d)

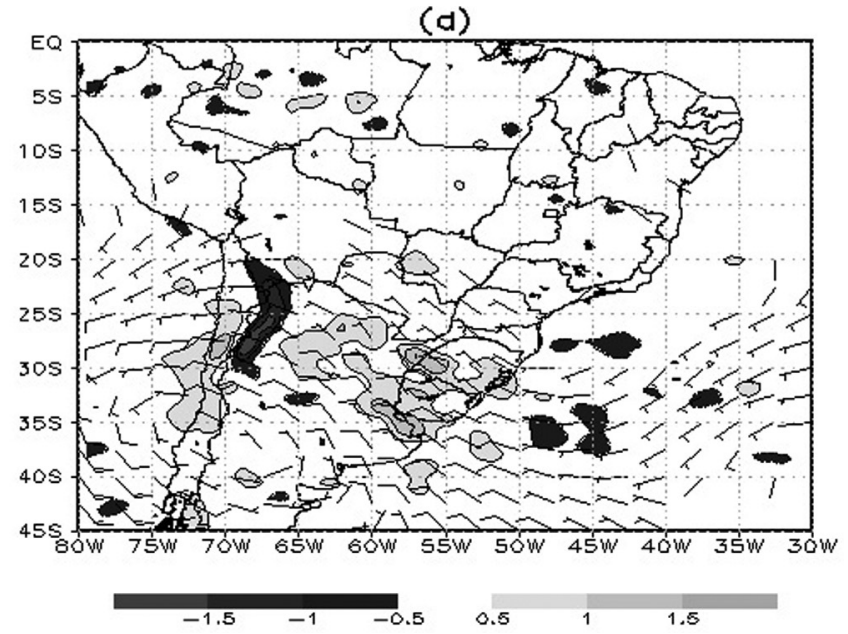

Figura 6 - Igual à Fig. 5, mas para os compostos correspondentes a dois dias antes da passagem dos sistemas frontais que causam chuvas mais intensas no Vale do Itajaí.

cavado anômalo em superfície. Esse cavado se estende para o sudeste dentro de um ambiente anomalamente aquecido (contornos na Fig. 6a) e úmido como consequência dos ventos anômalos de noroeste (Fig. 6b). O caráter frontal da perturbação localizada nas proximidades da fronteira com o Uruguai (ou seja, a frente fria que provocará chuvas intensas sobre o Vale do Itajaí dois dias depois) fica evidente principalmente através do forte gradiente de espessura 500/1000 hPa (Fig. 6a), do cavado frio e pouco baroclínico em 500 hPa centrado sobre a Patagônia (Fig. 6c), assim como do máximo relativo de vento e divergência nos altos níveis (Fig. 6d). A partir da posição frontal no dia -2 , pode-se deduzir que as frentes frias chuvosas avançam, em média, a menos de $20 \mathrm{~km} / \mathrm{h}$. Essa velocidade é bem inferior à média determinada por Rodrigues et al. (2004).

Nas $24 \mathrm{~h}$ prévias à passagem das frentes frias chuvosas pelo Vale do Itajaí (figura não mostrada), destaca-se o avanço geral da perturbação frontal e a intensificação das anomalias. Entre as mudanças mais importantes sobressai um aumento da anomalia positiva de espessura $500 / 1000 \mathrm{hPa}$ dentro da massa de ar pré-frontal, que pode estar associado tanto à presença de advecção quente como de subsidência pré-frontal provocada pela intensificação de uma crista corrente abaixo do cavado, destacada na Fig. 6c. Neste dia, as anomalias de temperatura e umidade tornamse máximas na região do Vale do Itajaí, contribuindo para o aumento da instabilidade termodinâmica. O campo de divergência anômalo também aparece bem mais organizado que nas $24 \mathrm{~h}$ anteriores. Esses elementos justificam o campo de chuva observado na Fig. $2 b$.

\subsection{Campos sazonais}

Sendo que os campos de anomalias mostrados anteriormente correspondem aos casos selecionados ao longo de todo o ano, é importante indagar a existência de diferenças sazonais, que podem se tornar de utilidade, por exemplo, para fins de previsão.

Em termos gerais, as diferenças sazonais, tanto nos aspectos dinâmicos quanto termodinâmicos, foram pequenas. Em particular, os campos de vento e umidade nos baixos níveis, fundamentais para o desenvolvimento de 
convecção, apresentaram variações muito pequenas entre ambos os semestres.

A Fig. 7 mostra as anomalias de pressão ao nível médio do mar e espessura 500/1000 hPa (painéis da esquerda) e de geopotencial e temperatura no nível de 500 hPa (painéis da direita) para os casos escolhidos durante o semestre frio (acima) e quente (abaixo). Esses campos são os que apresentaram as maiores diferenças sazonais dentre todos os analisados.

Em geral, a magnitude das anomalias não sofre fortes variações sazonais, indicando que as frentes que causam chuvas volumosas no Vale do Itajaí são igualmente anômalas ao longo de todo o ano. Contudo, a comparação entre a Figs. 7a e 7c revela que a perturbação em superfície apresenta uma onda ligeiramente mais curta durante o semestre frio (Fig. 7a) em comparação com o semestre quente (Fig. 7c), além de uma propagação mais zonal da onda térmica e uma maior penetração no continente do cavado frontal. Outra diferença interessante é que no semestre quente o gradiente de espessura 500/1000 hPa é mais intenso, indicando que durante esta estação apenas as frentes frias mais anômalas (sucedidas por declínios de temperatura mais acentuados) apresentam potencial para causar chuvas intensas no leste de Santa Catarina.

Nos níveis médios (Figs. 7b e 7d) também se pode apreciar um trem de ondas levemente mais zonal no período mais frio, onde a presença do cavado frio e pouco baroclínico é a característica mais marcante em ambas as épocas do ano. A posição do cavado é também diferente nas distintas épocas, posicionando-se mais para noroeste no semestre frio.

\subsection{Diferenças entre os casos chuvosos e não chuvosos}

Considerando que um dos objetivos principais deste artigo é identificar as condições atmosféricas associadas às frentes frias causadoras de chuvas intensas no litoral de Santa Catarina, esta seção analisa as diferenças nas condições dinâmicas e termodinâmicas entre as frentes frias chuvosas e não chuvosas. Tais diferenças permitirão identificar parâmetros com potencial para melhorar a previsão desse tipo situação.
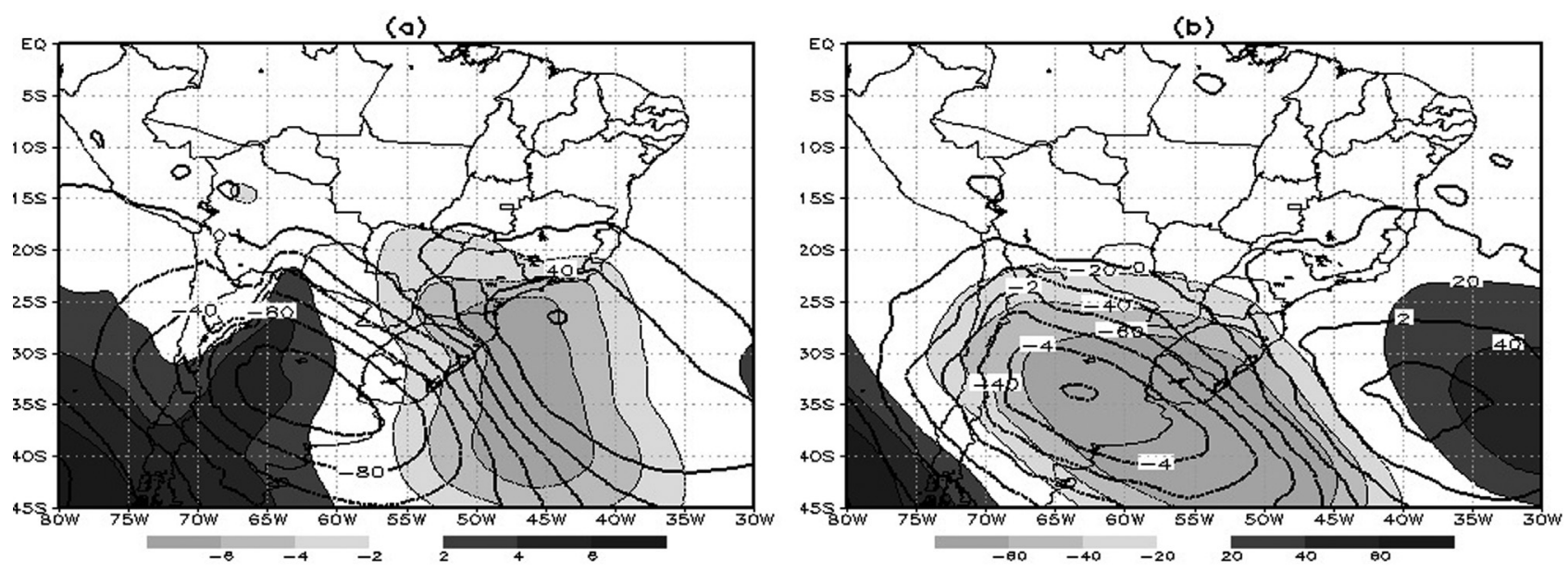

(c)
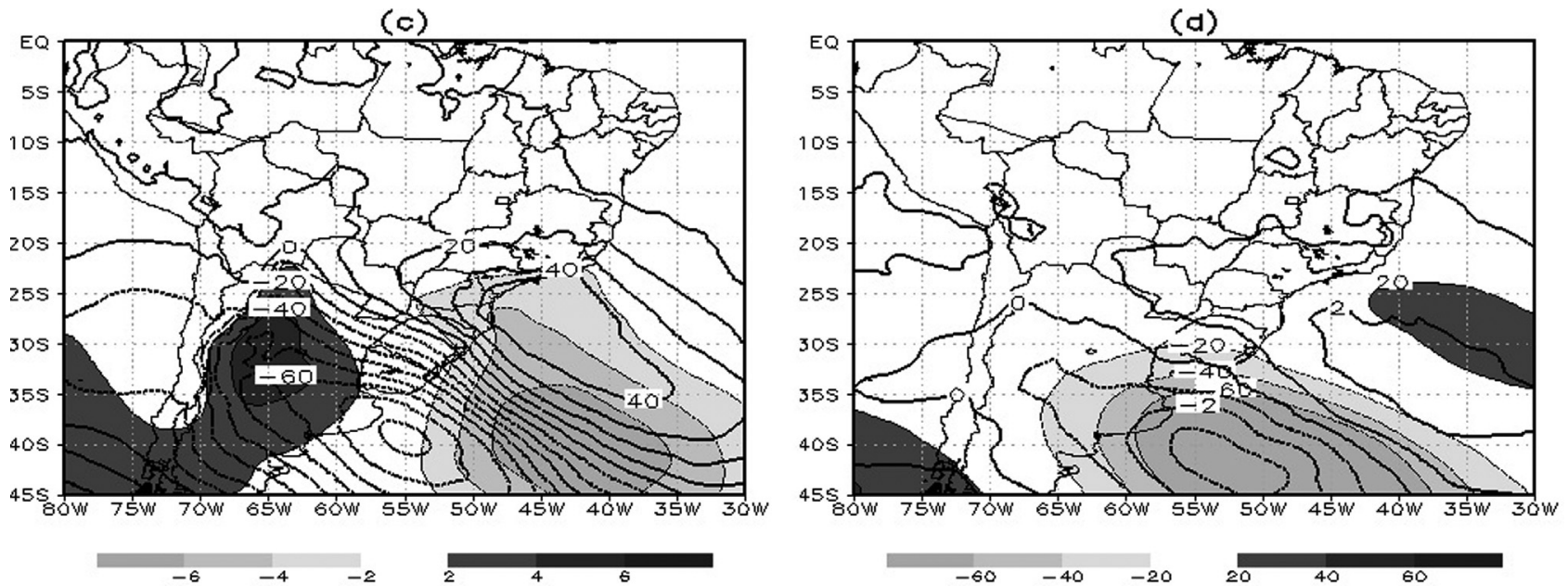

Figura 7 - Anomalia de a) pressão reduzida ao nível do mar (tons de cinza, hPa) e espessura 500/1000 hPa (contornos, m) e b) altura geopotencial (tons de cinza, $\mathrm{m}$ ) e temperatura (contornos, ${ }^{\circ} \mathrm{C}$ ) em $500 \mathrm{hPa}$ correspondentes às frentes frias que causam chuvas mais intensas no Vale do Itajaí no semestre frio (abril a setembro), c) igual a Fig. 7a) e d) igual a Fig. 7b) para os casos correspondentes ao semestre quente (outubro a março). 
A Fig. 8 apresenta mapas médios resultantes da subtração dos campos correspondentes aos casos chuvosos menos os casos não chuvosos. Na Fig. 8a (diferenças de pressão ao nível do mar e espessura 500/1000 hPa) torna-se evidente que as frentes frias chuvosas estão associadas a um cavado mais intenso na superfície (cinza claro), cuja influência estende-se até a Região Sudeste. O campo da diferença de espessura (contornos) mostra que a massa de ar pré-frontal é ligeiramente mais quente antes da passagem de uma frente fria chuvosa. Contudo, as diferenças mais notáveis ocorrem nas massas de ar pós-frontais, que são muito mais frias, determinando uma queda de temperatura mais acentuada, nos casos chuvosos. O anticiclone mais intenso sobre o Oceano Pacífico possivelmente resulta da superposição do Anticiclone Subtropical do Pacifico Sul e outro com características transientes. Embora as características térmicas pré-frontais sejam relativamente semelhantes, no nível de $850 \mathrm{hPa}$ o ambiente é consideravelmente mais úmido em termos quantitativos (cinza claro), o que indica uma maior energia potencial convectiva disponível. Esse fato está relacionado, muito provavelmente, ao escoa- mento mais intenso de noroeste (barbelas na Fig. 8b) que contribuem para a maior advecção de umidade desde a Amazônia. Nesse sentido, nota-se que tanto as diferenças de vento quanto as de umidade específica estendem-se desde o sul da Amazônia até o Oceano Atlântico, com um máximo localizado perto da divisa dos estados de Paraná e Santa Catarina. O máximo de vento de noroeste é também coerente com a maior intensidade do cavado em superfície (Fig. 8a). Por outro lado, o vento mais intenso de sudeste na retaguarda da frente fria, mostrado na Fig. 8b, explica o menor conteúdo de umidade na massa pós-frontal. Em consequência, as frentes frias que geram chuvas mais volumosas estão caracterizadas por um contraste de umidade específica mais elevado, o que pode impactar significativamente nas condições de instabilidade termodinâmica dominantes.

A Fig. 8c apresenta as diferenças médias de geopotencial (sombreado) e temperatura (contornos) no nível de $500 \mathrm{hPa}$, entre os casos chuvosos e não chuvosos. A partir dela, pode-se deduzir que as características detectadas nos níveis troposféricos mais baixos estão estreitamente rela-
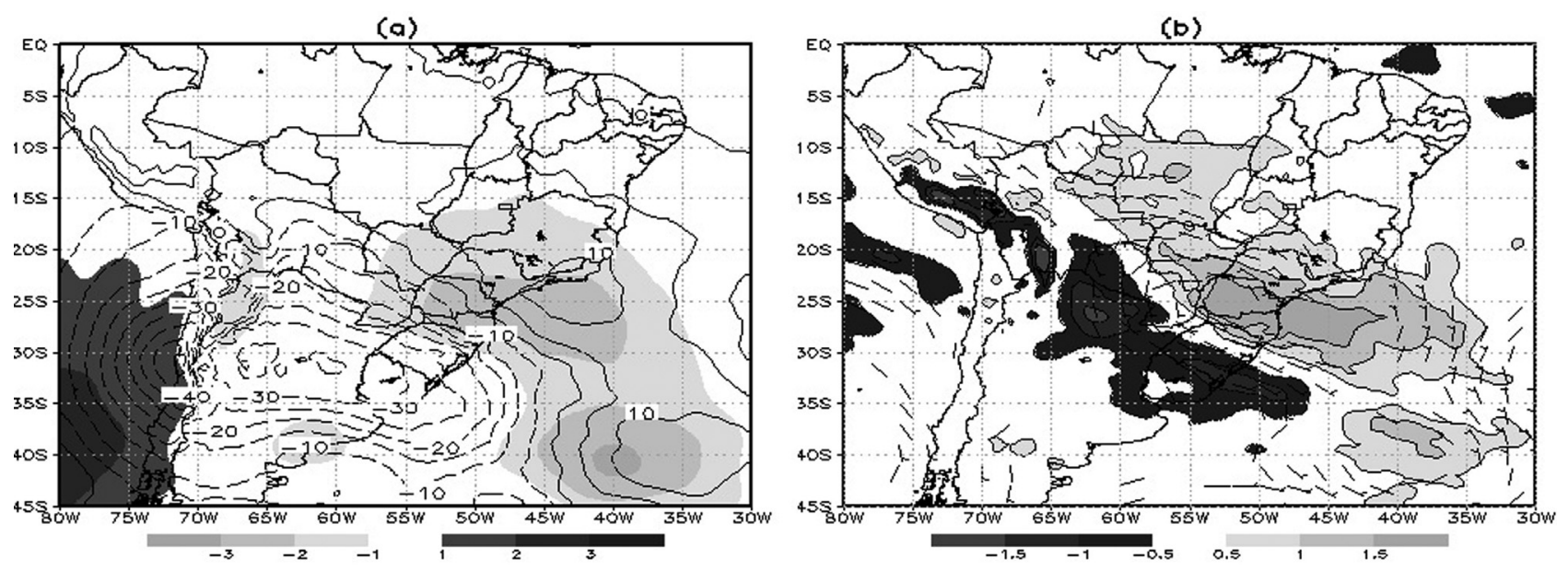

(c)
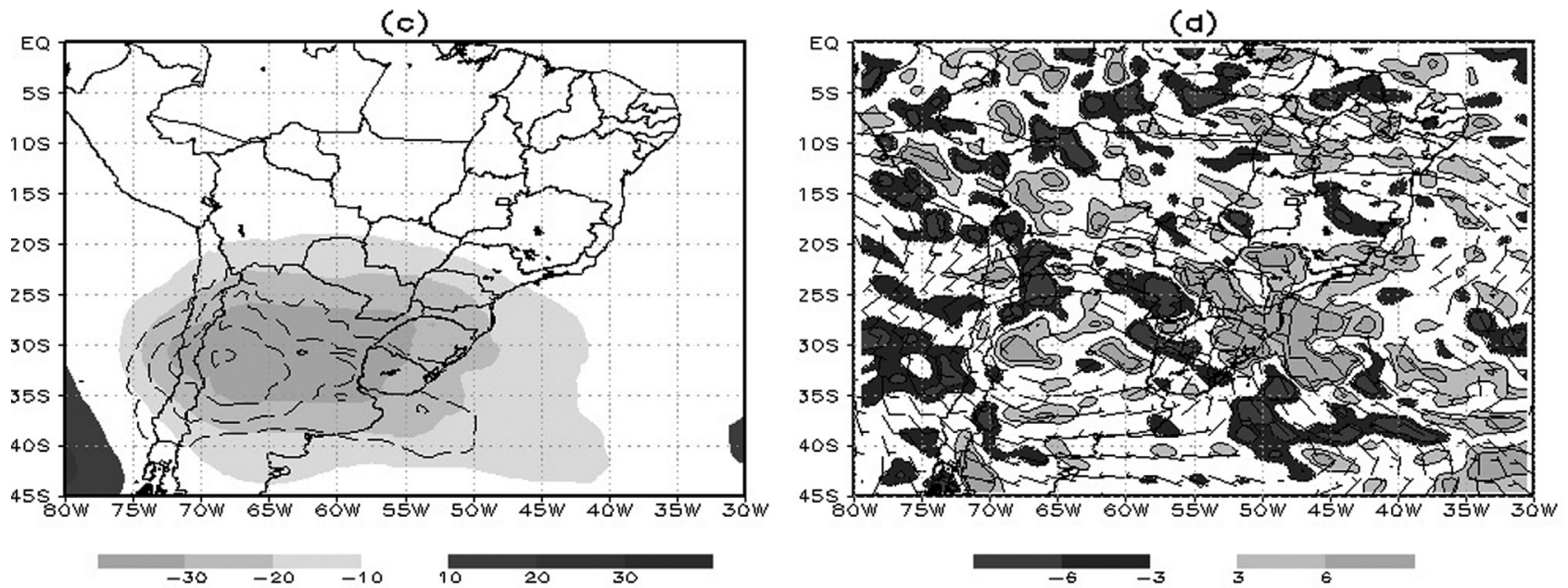

Figura 8 - Diferença média entre os campos dos casos "chuvosos" e "não chuvosos" nos dias de passagem de frentes frias pelo Vale do Itajaí: a) Pressão reduzida ao nível do $\mathrm{mar}(\mathrm{hPa})$ e espessura $500 / 1000 \mathrm{hPa}(\mathrm{m}), \mathrm{b})$ vento $(\mathrm{m} / \mathrm{s})$ e umidade específica $(\mathrm{g} / \mathrm{kg}) \mathrm{em} 850 \mathrm{hPa}(\mathrm{g} / \mathrm{kg})$, c) altura geopotencial $(\mathrm{mgp})$ e temperatura $\left({ }^{\circ} \mathrm{C}\right)$ em $500 \mathrm{hPa}$, d) vento $(\mathrm{m} / \mathrm{s})$, de temperatura $\left({ }^{\circ} \mathrm{C}\right)$ e de divergência $\left(10^{-6} \mathrm{~s}^{-1}\right)$ em $250 \mathrm{hPa}$. 
cionadas ao padrão de circulação nos níveis médios. Em particular, o trem de ondas na média troposfera é mais intenso (cristas e cavados mais acentuados) nos casos mais chuvosos, onde se destaca especialmente a presença de um cavado mais amplificado e frio centrado no oeste da Argentina, cuja influência se estende até o centro-sul do Brasil. A presença de um cavado mais intenso pode justificar a maior intensidade da anomalia negativa de pressão em superfície, que, por sua vez, força a advecção de umidade desde a Amazônia.

Finalmente, a Fig. 8d mostra que nos casos chuvosos o cavado associado nos altos níveis é também mais amplificado e apresenta uma inclinação consideravelmente menor à observada na metade inferior da troposfera. Ressalta-se a maior divergência de massa (cinza claro) presente na alta troposfera sobre a região de estudo durante a passagem das frentes chuvosas.

Em função da maior umidade existente nos baixos níveis e da menor temperatura observada na média troposfera nos casos chuvosos é possível deduzir um amento da instabilidade termodinâmica. A Fig. 9 apresenta os mapas médios do índice de levantamento (conhecido pelo nome em inglês: Lifted Index) para as frentes frias chuvosas (Fig. 9a) e não chuvosas (Fig. 9b), assim como a diferença entre eles (Fig. 9c). Os casos chuvosos estão associados a índices menores (maior instabilidade convectiva), em média inferiores a $2{ }^{\circ} \mathrm{C}$, enquanto que os casos não chuvosos apresentam índices superiores a $3{ }^{\circ} \mathrm{C}$. Outra diferença interessante é que o campo mostrado na Fig. 9a evidencia um eixo de maior instabilidade termodinâmica que passa exatamente pelo Vale do Itajaí e que se estende desde a Amazônia sobre a região de ventos de noroeste mais intensos. Nos casos não chuvosos a área de máxima instabilidade é mais difusa e apresenta um máximo relativo sobre o Estado de São Paulo. Contudo, a maior diferença entre os campos (mostrado na Fig. 9c) ocorre ao sul de $25^{\circ} \mathrm{S}$ sobre o centro-leste dos estados de Santa Catarina e Rio Grande do Sul e o oceano adjacente.

A Fig. 10 é semelhante à Fig. 8, mas para as 24 h prévias à passagem das frentes frias. Nesse momento, é esperável uma maior dispersão na posição das frentes individuais que compõem a média, sendo que elas normalmente se deslocam com velocidades diferentes. A superposição de ondas ligeiramente defasadas daria como resultado um campo mais suavizado e, portanto, com diferenças menores. Surpreendentemente, as diferenças entre os casos chuvosos e não chuvosos tornam-se ainda maiores um dia antes da passagem dos sistemas frontais pelo Vale do Itajaí. O aumento das diferenças é fisicamente consistente com o resultado mostrado na Fig. $2 b$, que aponta maiores volumes pluviométricos durante esse dia. Em particular, é possível identificar um maior gradiente de pressão e espessura através do sistema frontal (Fig. 10a), evidenciando sistemas transientes mais intensos. No nível de 850 hPa, (Fig. 10b) as diferenças de umidade específica incluem tanto um maior conteúdo de umidade sobre a massa de ar pré-frontal quanto uma maior secura sobre a massa fria da retaguarda, diretamente vinculado à presença de ventos mais anômalos nos casos chuvosos. Nos níveis médios e altos (Figs. 10c e 10d), esses casos também apresentam um cavado comparativamente mais frio e intenso, associado à maior divergência nos altos níveis, em comparação com as $24 \mathrm{~h}$ seguintes. Esses cavados são também sucedidos por cristas mais fortes e quentes. Coerentemente com o resultado anterior, a diferença entre os índices de levantamento é também maior no dia -1, pois os valores atingidos nos casos chuvosos são em média $0,5{ }^{\circ} \mathrm{C}$ mais baixos sobre o leste de Santa Catarina que os mostrados na Fig. 9 (figura não incluída).

As diferenças entre os casos chuvosos e não chuvosos podem ser também claramente identificadas com $48 \mathrm{~h}$ de antecedência (figura não mostrada). Em termos gerais, a frente fria que no dia -2 localiza-se, em média, nas proxi- (a)

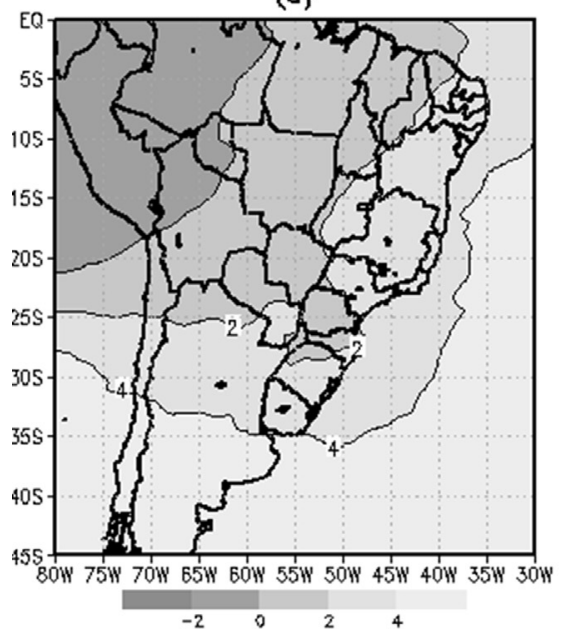

(b)

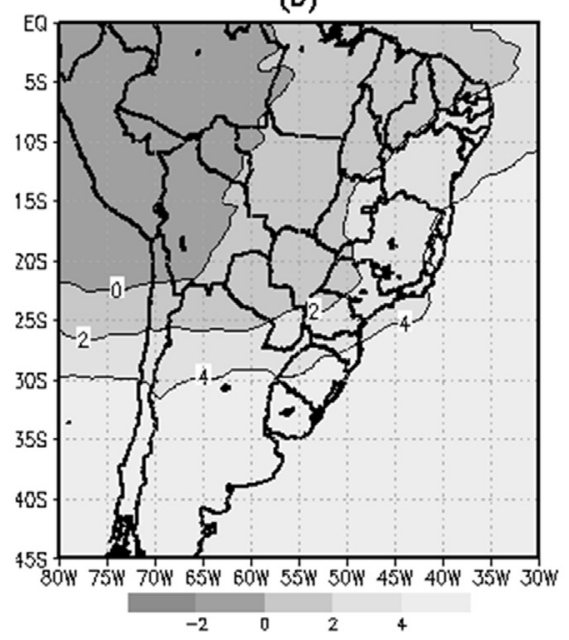

(b)

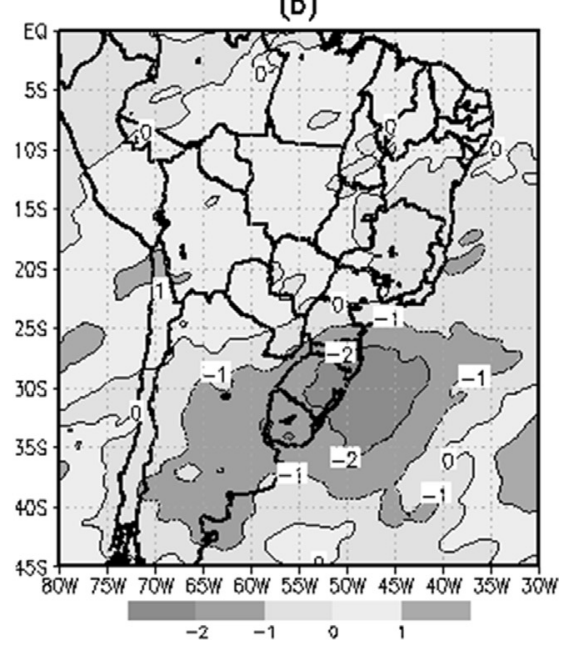

Figura 9 - Índices de levantamento (lifted Index) médios, em ${ }^{\circ} \mathrm{C}$, para o dia da passagem de frentes frias “chuvosas” (a), "não chuvosas” (b) pelo Vale do Itajaí. $\mathrm{O}$ painel da direita (c) corresponde à diferença entre os painéis (a) e (b). 
(a)

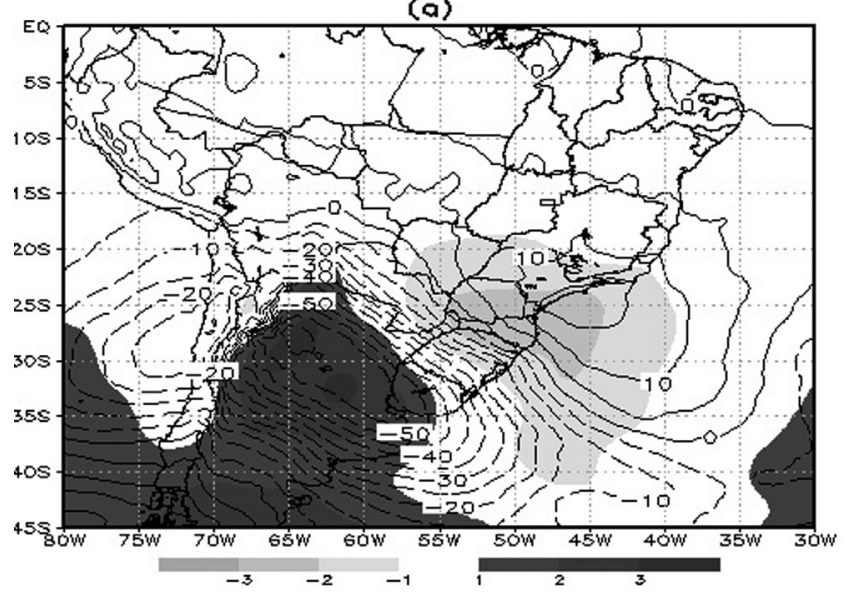

(c)

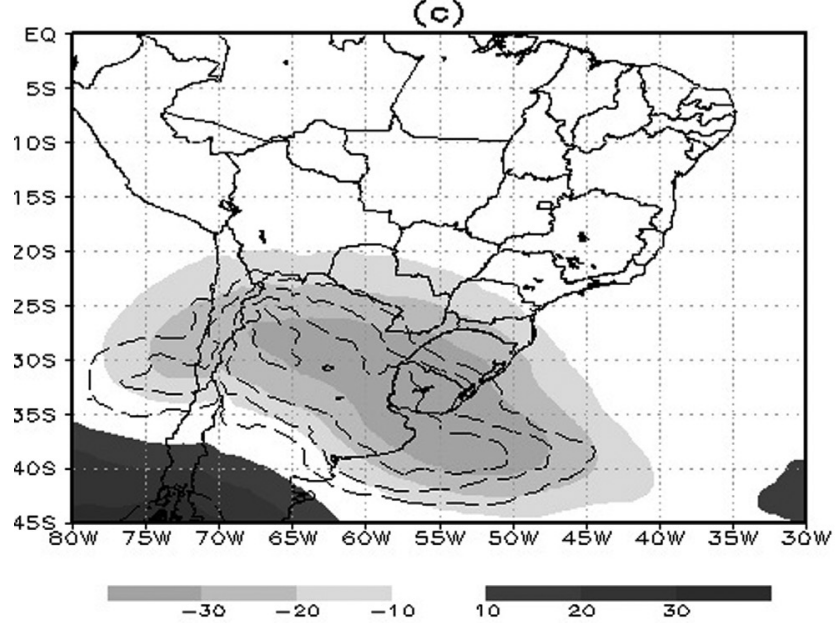

(b)

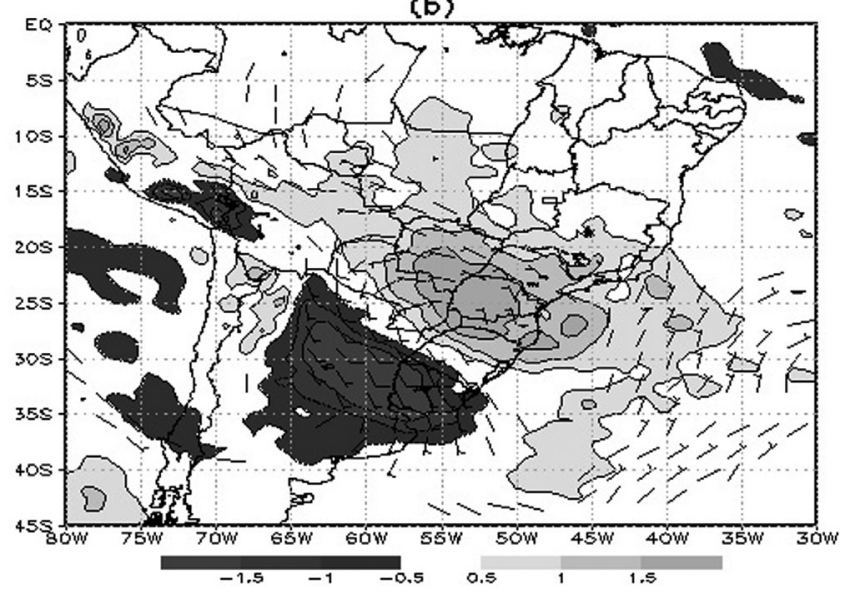

(a)

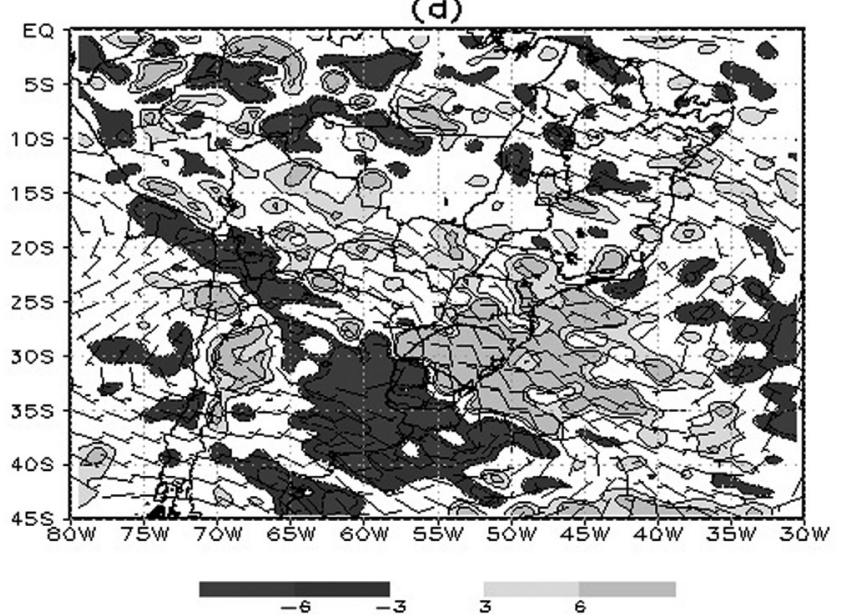

Figura 10 - Igual à Fig. 7 para os compostos correspondentes a um dia antes da passagem dos sistemas frontais "chuvosos" e "não chuvosos" no Vale do Itajaí.

midades da fronteira com o Uruguai (ver Fig. 5) está associada a um cavado em superfície, uma alta pós-frontal e um gradiente térmico mais intenso nos casos chuvosos. A comparação dos campos de umidade e vento no nível de $850 \mathrm{hPa}$ revela que já dois dias antes existe um maior conteúdo de umidade sobre o norte da Região Sul, incluído o leste de Santa Catarina, decorrente da atuação de ventos de noroeste mais intensos. Neste sentido, a evolução relativamente lenta da situação (a frente fria avança a menos de $20 \mathrm{~km} / \mathrm{h}$ ) pode ser um aspecto importante para o aumento da instabilidade convectiva nos dias precedentes, prolongando a advecção úmida pré-frontal.

Os padrões analisados previamente apresentam algumas variações na sua intensidade ao longo do ano, embora as principais características permaneçam inalteradas. Durante o semestre quente, os casos chuvosos destacam-se especialmente por apresentar maior umidade específica nos baixos níveis sobre a massa de ar pré-frontal, aumentando sua instabilidade termodinâmica. Outro ponto destacável é a maior divergência de massa nos altos níveis. Contudo, as cristas e cavados tanto nos baixos quanto nos médios níveis não apresentam diferenças importantes com respeito aos casos não chuvosos. No semestre frio, as frentes frias chuvosas apresentam um cavado comparativamente mais intenso e frio no nível de $500 \mathrm{hPa}$ e mais intenso nos baixos níveis. Embora a massa pré-frontal não apresente maiores diferenças no conteúdo de umidade, em comparação com a média anual (Fig. 10b), a área com diferenças positivas é muito mais generalizada, incluindo a totalidade da Região Sul e a maior parte das regiões Centro-Oeste e Sudeste.

\section{Conclusões}

Este trabalho analisa as características dinâmicas e termodinâmicas mais importantes associadas à passagem de frentes frias causadoras dos maiores volumes pluviométricos diários no Vale do Itajaí, região que apresenta um longo histórico de desastres naturais de natureza hidrometerológica. Os casos de frentes frias foram escolhidos objetivamente dentro da área de interesse (leste de Santa Catarina) e divididos em frentes frias chuvosas (5\% mais chuvoso da amostra sobre o Vale do Itajaí) e não chuvosas (5\% menos chuvoso). 
As frentes frias que causam os maiores acumulados pluviométricos podem ocorrer ao longo de todo o ano e apresentam forte variabilidade interanual, embora não tenha sido possível estabelecer nenhuma vinculação com ondulações de grande escala e/ou longo período.

Os campos médios e de anomalias correspondentes a frentes frias que causam chuvas extremas no Vale do Itajaí, e fundamentalmente suas diferenças com respeito aos casos pouco chuvosos, permitem identificar características dinâmicas e termodinâmicas com potencial para compreender os mecanismos atmosféricos envolvidos, assim como para prever este tipo de situação. Essas características são resumidas a seguir:

O cavado frontal na troposfera média e alta é mais intenso, sendo mais quente nos níveis superiores (provavelmente devido a um abaixamento mais acentuado da tropopausa) e mais frio na troposfera média. A maior divergência de massa nos altos níveis e a advecção de vorticidade ciclônica mais intensa na troposfera média favorecem a ocorrência de movimentos ascendentes mais vigorosos. A perturbação ciclônica apresenta baixa inclinação entre a média e a alta troposfera $(250 / 500 \mathrm{hPa})$, evidenciando um sistema relativamente barotrópico e, portanto, lento.

A aproximação da perturbação nos altos níveis força a formação/intensificação de um cavado nos níveis mais baixos da atmosfera, mais intenso que nos casos pouco chuvosos, que pode estar associado à presença prévia da Baixa do Chaco. Esse processo provoca o aumento dos ventos de noroeste numa faixa que se estende desde a Amazônia até o leste de Santa Catarina.

O aumento da advecção de ar quente e, especialmente, úmido desde o noroeste nas camadas mais baixas da atmosfera, combinado com a aproximação do cavado frio nos níveis médios (comparativamente mais frio que nos casos menos chuvosos), incrementa gradativamente a instabilidade termodinâmica sobre o leste de Santa Catarina.

A baixa velocidade de deslocamento das frentes frias chuvosas (aproximadamente 50\% menor em comparação com as frentes frias que passam pelo litoral de Santa Catarina) permite um aumento maior e mais persistente da energia potencial convectiva, que resulta máxima nas $24 \mathrm{~h}$ anteriores à passagem frontal. Por essa razão, os maiores volumes pluviométricos encontrados (provavelmente convectivos), em média, são de tipo pré-frontal.

As frentes frias que causam chuvas mais volumosas no Vale do Itajaí (superiores a $20 \mathrm{~mm} / 24 \mathrm{~h}$ ) apresentam uma forte inclinação nos primeiros $1500 \mathrm{~m}$ de altura (apesar da baixa baroclinia da perturbação nos níveis médios e altos), o que pode contribuir para o aumento dos movimentos verticais nas camadas mais baixas. $\mathrm{O}$ contraste de temperatura e umidade através da superfície frontal é também maior que nas frentes frias menos chuvosas. O maior contraste de umidade deve-se especialmente ao maior conteúdo de vapor d’água dentro da massa de ar pré-frontal, o que reforça a importância do persistente transporte de umidade desde a Amazônia ocidental.

A situação descrita anteriormente apresenta relativamente poucas variações sazonais, o que dá robustez aos resultados obtidos a partir da amostra anual, sendo mais marcantes as características termodinâmicas (dinâmicas) no verão (inverno). Durante o semestre quente, as frentes chuvosas se caracterizam por apresentar um maior contraste de temperatura e umidade nos níveis mais baixos, o que significa que apenas as frentes frias mais intensas apresentam potencial para provocar chuvas volumosas no Vale do Itajaí. No inverno a característica mais destacada é a intensidade e estrutura do cavado frontal na média troposfera, que apresenta um núcleo comparativamente mais frio em relação às frentes não chuvosas.

Em geral, a lenta evolução da situação meteorológica descrita acima permite identificar os principais elementos preditores com pelo menos $48 \mathrm{~h}$ de antecedência. Ainda, as maiores diferenças entre os casos chuvosos e não chuvosos ocorrem com uma antecedência de 24 h, resultado encorajador do ponto de vista da previsão de possíveis desastres naturais.

Trabalhos futuros pretendem utilizar os resultados alcançados nesta pesquisa para desenvolver metodologias objetivas de previsão.

\section{Agradecimentos}

Este trabalho foi parcialmente financiado pelo Conselho Nacional de Desenvolvimento Científico e Tecnológico (CNPq) através do projeto 473149/2012-5.

\section{Referências}

CEDEP, ATLAS BRASILEIRO DE DESASTRES NATURAIS 1991-2012, Volume Brasil, 2a Edição revisada e ampliada, Universidade Federal de Santa Catarina, Florianópolis, 127 p, 2013.

ANDRADE, K.M. Climatologia e comportamento dos sistemas frontais sobre a América do Sul. Dissertação de Mestrado em Meteorologia, Instituto Nacional de Pesquisas Espaciais, São José dos Campos, 185 pg.,2005.

BROOKS H.E.; LEE, J.W; CRAVE, J.P. The spatial distribution of severe thunderstorm and tornado environments from global reanalysis data. Atmospheric Research, v. 67, p. 73-94, 2003.

BROOKS, H.E. A global view of severe thunderstorms: Estimating the current distribution and possible future changes In: Preprints, Severe Local Storms Special Symposium, American Meteorological. Society, Atlanta, EUA. Anais Eletrônicos...www.nssl.noaa.gov/users/brooks/public_html/papers/AMS2K6.pdf., 2006.

CATTO, J.; JAKOB, C.; BERRY, G.; NICHOLS, N. Relating global precipitation to atmospheric fronts. Geophys. Res. Lett., v. 39, n. 10, p. 1-6, 2012.

CAVALLO, E.; NOY, I. The Economics of Natural Disasters: A Survey. IDB Working Paper 124. Washington, DC, United States: Inter-American Development Bank. 
CAVALCANTI, I.F.A.; KOUSKY, V.E. Climatology of South American cold fronts. International Conference on Southern Hemisphere Meteorology and Oceanography, 7, Wellington, New Zealand. Proceedings. New Zealand: American Meteorological Society, 2003.

CAVALCANTI, I.F.A.; KOUSKY, V.E. Frentes Frias sobre o Brasil. In: Iracema F. A. Cavalcanti; Nelson J. Ferreira, Maria Justi da Silva; Maria Assunção S Dias. (Org.). Tempo e Clima no Brasil. São Paulo: Oficina de textos, 2009.

ESCOBAR G., Jatos de Altos Níveis, In: In: IRACEMA F.A. CAVALCANTI; NELSON J. FERREIRA, MARIA JUSTI DA SILVA; MARIA ASSUNÇÃO S. DIAS (Org.). Tempo e Clima no Brasil. São Paulo: Oficina de textos, 2009.

GAN, M.A.; RAO, V.B. The Influence of the Andes Cordillera on transient disturbances. Monthly Weather Review, v. 122, n. 6, p. 1141-1157, 1994.

GARREAUD, R.D. Cold Air Incursions over Subtropical South America: Mean Structure and Dynamics, Monthly Weather Review, v. 128, n. 7, p. 2544-2559, 2000.

HIRSCHBERG, P.A.; FRITSCH, J.M. Tropopause Undulations and the Development of Extratropical Cyclones. Part I. Overview and Observations from a Cyclone Event, Monthly Weather Review, v. 119, n. 2, p. 496-517, 1991.

MAY, W. Variability and extremes of daily rainfall during the Indian summer monsoon in the period 1901-1989, Global and Planetary Change, v. 44, n. 1, p. 83-105, 2004.

RIBEIRO, B.Z.; SELUCHI, M.E., CHOU, S.C. Synoptic climatology of warm fronts in Southeastern South America, In- ternational Journal of Climatology, v. 36, n. 2, p. 644-655, 2016.

RODRIGUES, M.L.; FRANCO, F.; SUGAHARA, S. Climatologia de Frentes Frias no Litoral de Santa Catarina. Revista Brasileira de Geofísica, v. 22, n. 2, p. 135-151, 2004.

ROZANTE, J.R.; MOREIRA, D.S.; GONÇALVES, L.G.G. Combining TRMM and Surface Observation Precipitation: Technique and Validation Over South America. Weather and Forecasting, v. 25, n. 3, p. 885-894, 2010.

SAHA, S. et al. The NCEP climate forecast system reanalysis. Bulletin of the American Meteorological Society, v. 91, n. 8, p. 1015-1057, 2010.

SALIO, P.; NICOLINI, M.; ZIPSER, E.J. Mesoscale convective systems over southeastern South America and their relationship with the South American low-level jet. Monthly Weather Review, v. 135, n. 4, p. 1290-1309, 2007.

SELUCHI, M.E.; GARREAUD, R.; NORTE, F.A.; SAULO, A. C. Influence of the subtropical Andes on baroclinic disturbances: A cold-front case study. Monthly Weather Review, v. 134, n. 11, p. 3317-3335, 2006.

SELUCHI, M.E; SAULO, A.C. Baixa do Noroeste da Argentina e Baixa do Chaco: Características, Semelhanças e Diferenças. Revista Brasileira de Meteorologia, v. 27, n. 1, p. 49-60, 2012.

TEIXEIRA, M.S.; SATYAMURTY, P. Dynamical and synoptic characteristics of heavy rainfall episodes in southern Brazil. Monthly Weather Review, v. 135, n. 2, p. 598-617, 2007.

This is an Open Access article distributed under the terms of the Creative Commons Attribution Non-Commercial License which permits unrestricted non-commercial use, distribution, and reproduction in any medium provided the original work is properly cited. 